\title{
BMJ Open A service-level action research intervention to improve identification and treatment of cannabis and related mental health issues in young Indigenous Australians: a study protocol
}

\author{
India Bohanna, ${ }^{1}$ Katrina Bird, ${ }^{1}$ Jan Copeland, ${ }^{2}$ Nicholas Roberts, ${ }^{1}$ Alan Clough ${ }^{1}$
}

To cite: Bohanna I, Bird K, Copeland J, et al. A servicelevel action research intervention to improve identification and treatment of cannabis and related mental health issues in young Indigenous Australians: a study protocol. BMJ Open 2014;4:e005689.

doi:10.1136/bmjopen-2014005689

- Prepublication history for this paper is available online. To view these files please visit the journal online (http://dx.doi.org/10.1136/ bmjopen-2014-005689).

Received 13 May 2014 Revised 13 July 2014 Accepted 15 July 2014

\section{CrossMark}

For numbered affiliations see end of article.

Correspondence to Dr India Bohanna; india.bohanna@jcu.edu.au

\section{ABSTRACT}

Introduction: Regular cannabis use is associated with negative mental health impacts including psychosis, depression and anxiety. Rates of cannabis use have increased in Aboriginal and Torres Strait Islander communities in northern Australia within the last two decades, presenting a significant increased risk to young people's mental health in these regions. Improved screening, early detection and treatment for cannabis-related mental health issues are urgently required. This paper describes a service-level action research intervention and evaluation protocol for use in the few services where it is possible to engage young Aboriginal and Torres Strait Islander Australians.

Methods/Design: The protocol is being developed in two services where youth mental health is core business: a primary healthcare centre and a youth service in the Cairns and hinterland region, far north Queensland. The protocol calls first for baseline data to be collected using staff and client surveys; network mapping; and analysis of screening, treatment and referral rates. The protocol's intervention phase is driven by service needs identified from baseline data. Intervention strategies focus on implementing/enhancing cannabis screening instruments and processes in line with current best practice; enhancing networks with external drug and mental health services; developing culturally acceptable training and resources; developing activities aiming to reduce cannabis use in young Aboriginal and Torres Strait Islander clients using the services. The protocol requires implementation of the multilevel intervention within each service for 1 year, with follow-up data then collected and compared to baseline. Process evaluation identifies the more effective intervention strategies and documents the challenges to be overcome for full implementation.

Ethics and dissemination: Ethics approval was provided by The James Cook University, Human Research Ethics Committee. Ethics Approval Number H5322. Peer-reviewed publications will also be used to disseminate the finding. Results will also be discussed with stakeholder organisations.

\section{INTRODUCTION}

Aboriginal and Torres Strait Islander youth are at significantly greater risk of developing substance use and mental health disorders compared to their non-Indigenous counterparts. They are around twice as likely to be hospitalised or die from injury; six times more likely to die from assault and four times more likely to die from suicide. ${ }^{1} \mathrm{Up}$ to $15 \%$ of the 10-year life expectancy gap between Indigenous and non-Indigenous Australians is attributed to mental health conditions, ${ }^{2}$ and Indigenous young people aged 12-24 years are hospitalised for mental and behavioural disorders three times more often than non-Indigenous young people. ${ }^{3}$

Cannabis use can be a significant contributor to poor mental health, particularly when it begins at a young age. ${ }^{5}$ The adverse mental health effects of cannabis use in the general population are increasingly recognised, including anxiety, depression, ${ }^{6-8}$ psychotic disorders, ${ }^{4}{ }^{9-12}$ dependence $^{6} \quad 7 \quad 13$ withdrawal ${ }^{1415}$ and cognitive impairment. ${ }^{1617}$ Starting to use cannabis before age 15 is associated with an increased likelihood of developing later psychotic disorders, increased risk of dependence, other drug use, and poor educational and psychosocial outcomes. $^{5}$

In Australia, little is known about the links between cannabis use and poor mental health in the young Aboriginal and Torres Strait Islander Australian population. Although this segment of the population has proven to be extremely difficult to engage for health promotion, prevention, service provision and research, ${ }^{18-21}$ recent surveys demonstrate that the prevalence of cannabis use in 
the Aboriginal and Torres Strait Islander Australian population in remote and very remote regions of northern Australia is very high in young people. In remote far north Queensland, $66 \%$ of men and $30 \%$ of women were currently using cannabis in a recent survey. ${ }^{22}$ In remote communities in the Northern Territory, rates of use as high as $67 \%$ of Aboriginal and Torres Strait Islander men and $22 \%$ of Aboriginal and Torres Strait Islander women were reported earlier, half regular (daily) users $^{23}$ and around one-fifth meeting criteria for cannabis dependence or moderate-severe depression. ${ }^{24}{ }^{25}$ This is in stark contrast with estimates from surveys of the general Australian population, in which $10.3 \%$ of adults surveyed in 2010 reported using cannabis within the past year, $13 \%$ of users reporting daily use ${ }^{26}$ and of those surveyed aged between 14 and 18; just $15.7 \%$ had reportedly used cannabis in the past 12 months. $^{26}$

In the only study to examine the self-reported qualitative mental health impacts of cannabis published so far for Aboriginal and Torres Strait Islander populations, one in four current users may be suffering from negative mental health effects due to cannabis. ${ }^{22}$ Reinforcing these limited data, Hunter et $a l^{27}$ reported that the prevalence of psychosis in Aboriginal and Torres Strait Islander Australians in north Queensland was double that of the general Australian population, with cannabis playing a significant role in the onset of psychotic disorders in $50-59 \%$ of diagnoses. There are no data available, at all, for the much larger populations of Aboriginal and Torres Strait young people who live in metropolitan and regional centres.

Addressing cannabis use issues and recognising the importance of reducing early onset use in preventing dependence, mental illness and negative psychosocial outcomes in Aboriginal and Torres Strait Islander young people should be a high priority. ${ }^{25}{ }^{28-30}$ Despite this, there are no published intervention strategies that have been shown to be effective in reducing cannabis use and mental health issues in any population of Aboriginal and Torres Strait Islander young people.

\section{Objectives}

The key objectives of this protocol are to:

1. Enhance the capacity of the few youth services and health services in regional centres in Queensland who have the capacity to engage with Aboriginal and Torres Strait Islander youth so that they can more routinely document cannabis use rates and effectively identify, refer, treat and respond to cannabis and related mental health issues in their clients, and;

2. Develop and implement intervention strategies to improve identification and treatment of cannabis and related mental health issues in young Indigenous clients within these services, using an action research approach;

3. Evaluate the effectiveness of the intervention strategies by comparing baseline data collected in item 1 with follow-up data, and conducting process evaluation.

\section{METHODS/DESIGN}

Study design and setting

This study will use a participatory action research approach $^{31}$ within services to influence practice and effect sustainable change at the service level. This approach is endorsed for Aboriginal and Torres Strait Islander research given that it emphasises participation by the people being studied, cultural respect, capacity building and collaboration. ${ }^{32}$ The key features of the action research approach to be used in this study are 'cyclical activities involving examination of existing processes, change monitoring the apparent effects of the change, and further change'. ${ }^{33}$ This will help the services develop and implement practical strategies to improve the identification and treatment of cannabis and related mental health issues in their young Indigenous clients. The participatory approach encourages the services and staff to take ownership of the research and contribute to the development of sustainable changes in practice. ${ }^{31}$ In this study, the targets of the intervention are the services. The intervention is conducted at a service level and thus does not seek to reduce cannabis use rates in young Aboriginal and Torres Strait Islander clients directly through individuallevel strategies. Nevertheless, examination of changes in cross-sectional client cannabis use will be included.

The research will be conducted across Queensland. The protocol is being developed and tested in far north Queensland, and in two services in the Cairns and hinterland region. The participating services were chosen because they were keen to participate in the research; one is an Aboriginal community controlled primary health service and the other is a community-based service that works with vulnerable and hard-to-engage young people, the majority of whom are Aboriginal or Torres Strait Islanders. The primary healthcare service provides for a population of 764 Indigenous Australians aged 10-24 years, which represents $28.5 \%$ of a total of 2677 Indigenous persons in the local population. ${ }^{34}$ The community-based youth service serves a population of approximately 4338 Indigenous young people aged 10 24 years, which represents $30.1 \%$ of a total of 14391 Indigenous persons in the local population. ${ }^{34}$ The client base of both services includes a significant number of young people who move between the regional centre and the remote and very remote communities of far north Queensland.

As shown in figure 1, this protocol calls for the research to be conducted over 2 years: Objective 1 (6 months), Objective 2 (12 months) and Objective 3 (6 months).

\section{Data collection}

Data collected at baseline and follow-up are shown in table 1. Data collection methods include staff and client surveys, process mapping, network mapping and document scans. Participants in the research include both staff and clients at each service involved. All staff in the 


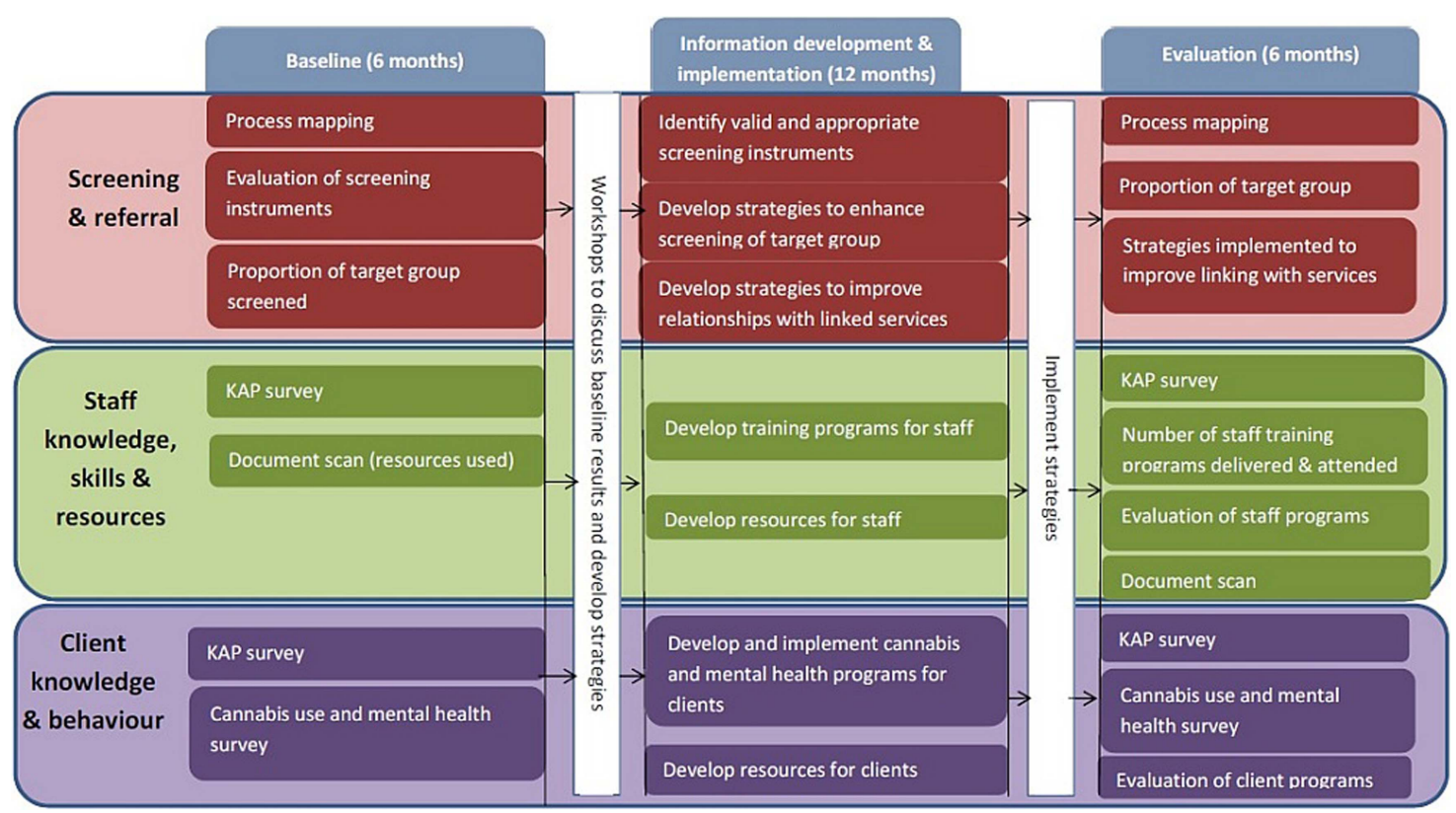

Figure 1 Timeline of research/concept diagram.

services are invited to participate, and to complete the same survey at baseline and follow-up, addressing key issues in cannabis-related knowledge, attitudes and practice (table 2).

Client surveys are to be conducted at baseline and follow-up to determine any changes in cannabis use rates (table 3). Aboriginal and Torres Strait Islander clients aged between 12 and 24 years will be invited to participate in the surveys, which will be conducted in waiting rooms or another suitable situation during baseline and follow-up.

Client surveys will be used to determine cannabis use patterns and mental health status incorporating the following questionnaires: the Adolescent Cannabis Problems Questionnaire (CPQ-a) ${ }^{35}$ Patient Health Questionnaire 9 (PHQ-9), ${ }^{36}$ Generalised Anxiety Disorder 7 (GAD-7) ${ }^{37}$ and Strong Souls. ${ }^{38}$

Network and process mapping will be used to identify the relationships that exist with organisations surrounding both the services. Network mapping will be used in this study to show how each organisation interacts with the service, including client referrals and resources. ${ }^{39}$ It identifies influential organisations within the services network, and outlines the paths used by the services to seek support for clients. ${ }^{40}$

Process evaluation using realist evaluation techniques ${ }^{41}{ }^{42}$ is included to determine if the intervention strategies were implemented as intended, and to fully describe any barriers to successful implementation. Realist evaluation in this study seeks to identify the mechanisms by which service practices work or not in the health service and the youth service contexts. Using information collected in interviews with service staff, using service records and documents as well as information from interviews with staff in other services in the network, these mechanisms will first be identified and discussed with participating service staff to reach a consensus. In group discussions, the way these mechanisms

\begin{tabular}{lll} 
Table 1 Data collection & & Data source \\
\hline Method & Data collected & Service data \\
\hline Service system data & Client demographic information & Service data \\
analysis & Client primary drug of concern & Service data \\
& Number of clients screened for cannabis in previous 12 months & Staff \\
Survey & Screening, referral, treatment practices for cannabis and mental health & Staff \\
& issues & Clients \\
Semi-structured interviews & Cannabis knowledge, attitudes and practice & Staff \\
& Cannabis use information & Staff, stakeholders \\
Process mapping & Process evaluation & Staff \\
Network mapping & Flow of patients through the service, screening and referral points & Staff \\
Document scan & Referral pathways, opportunities to strengthen inter-service relationships & Staff
\end{tabular}




\begin{tabular}{|c|c|}
\hline Domain & Item content \\
\hline Knowledge & $\begin{array}{l}\text { Lifetime cannabis use rates (total Australian population, Indigenous Australian population, Cape York population) } \\
\text { Current cannabis use rates (total Australian population, Indigenous Australian population, Cape York population) } \\
\text { Daily cannabis use rates (total Australian population, Indigenous Australian population, Cape York population) } \\
\text { Gender-related differences in use } \\
\text { Quit intentions (derived from Cape York cannabis research) } \\
\text { Impacts on physical health, mental health and cognitive function } \\
\text { Cost per gram-national, local, Cape York } \\
\text { Symptoms of dependence } \\
\text { Age-related risk of dependence } \\
\text { Effective treatments for cannabis dependence } \\
\text { Recognition of presence of a cannabis screening policy within the service } \\
\text { Recognition of presence of a mental health screening policy within the service }\end{array}$ \\
\hline Attitudes & $\begin{array}{l}\text { Legal status of cannabis use } \\
\text { Medicinal use } \\
\text { Harms related to cannabis (mental health, physical health, dependence) } \\
\text { Psychosocial impacts (crime, education, other drug use) } \\
\text { Perceptions of young cannabis users' attitudes towards screening and treatment } \\
\text { Utility and benefits of screening for cannabis use } \\
\text { Satisfaction with level of knowledge } \\
\text { Satisfaction with skills in screening and treating cannabis-related issues } \\
\text { Satisfaction with existing resources } \\
\text { Satisfaction with training in cannabis-related issues }\end{array}$ \\
\hline Practice & $\begin{array}{l}\text { Number of clients screened, referred or treated for cannabis use in the previous month } \\
\text { Number of clients screened, referred or treated for mental health issues in the previous month } \\
\text { Barriers to screening and treatment for cannabis use issues } \\
\text { Opportunities to improve confidence in screening and treating cannabis use }\end{array}$ \\
\hline
\end{tabular}

are believed to operate will be mapped. At this theoretical level, the influence of the network of collaborating service providers, the context, will be considered in order to design practical and acceptable ways of making these mechanisms more effective. The intervention will be tested by implementing it. In a series of learning and information-sharing sessions with staff, the effectiveness of the intervention will be assessed. Using this method, any changes to the intervention strategies identified by staff or stakeholders as necessary will be implemented,

Table 3 Client cannabis use survey

\begin{tabular}{|c|c|}
\hline $\begin{array}{l}\text { Cannabis and other } \\
\text { drug use }\end{array}$ & $\begin{array}{l}\text { Current drug use (cannabis and } \\
\text { other drugs) } \\
\text { Type, frequency and quantity of } \\
\text { drug use } \\
\text { Age of first use } \\
\text { Financial expenditure on cannabis } \\
\text { Method of use }\end{array}$ \\
\hline $\begin{array}{l}\text { Readiness to } \\
\text { change }\end{array}$ & $\begin{array}{l}\text { Intention to quit or cut down } \\
\text { Readiness to change }\end{array}$ \\
\hline Mental Health & $\begin{array}{l}\text { Current and past experience of } \\
\text { symptoms of anxiety, depression, } \\
\text { psychosis (GAD-7, PHQ-9, Strong } \\
\text { Souls) }\end{array}$ \\
\hline $\begin{array}{l}\text { Demographic } \\
\text { information }\end{array}$ & $\begin{array}{l}\text { Gender, age, Aboriginal and/or } \\
\text { Torres Strait IslanderHighest level } \\
\text { of education attained }\end{array}$ \\
\hline
\end{tabular}

thus refining the strategies. The intervention will include the design of suitable data collection tools for monitoring changes in service performance. The realist evaluation approach uses participatory action research in this way to evaluate what works for whom and in what context. The process evaluation plan is shown in table 4 .

\section{Intervention}

Following baseline data collection, the protocol calls for one workshop to be held at each service with staff and key stakeholders to achieve Objective 1. Consistent with the action research approach, researchers work with staff to interpret the results of Objective 1, and to achieve Objective 2 they develop interventions that are feasible, practical and readily implementable within the service. The workshop will be used to:

1. Identify/develop and implement valid and effective screening instruments and processes;

2. Develop and implement strategies to enhance screening of the target groups;

3. Develop and implement strategies to improve relationships with external services;

4. Identify/develop and implement cannabis and mental health training and resources for service staff to enhance knowledge and skills;

5. Identify/develop and implement activities to reduce cannabis and mental health issues in young Aboriginal and Torres Strait Islander clients. 
Table 4 Process evaluation design with realist evaluation framework following realist evaluation principles outlined by Pawson et $\mathrm{al}^{41}$ and Pawson and Tiller ${ }^{42}$

\begin{tabular}{|c|c|c|c|c|}
\hline $\begin{array}{l}\text { Realist } \\
\text { evaluation } \\
\text { component }\end{array}$ & $\begin{array}{l}\text { Process evaluation } \\
\text { component }\end{array}$ & Data sources & $\begin{array}{l}\text { Data collection } \\
\text { timetable }\end{array}$ & Data analysis \\
\hline \multirow[t]{3}{*}{ Context } & $\begin{array}{l}\text { Process and service } \\
\text { network mapping }\end{array}$ & $\begin{array}{l}\text { Interviews with service } \\
\text { staff }\end{array}$ & Baseline & $\begin{array}{l}\text { Qualitative/thematic changes } \\
\text { and network analysis }\end{array}$ \\
\hline & & Service document scan & $\begin{array}{l}\text { Baseline and } \\
\text { follow-up }\end{array}$ & $\begin{array}{l}\text { Monitoring for key } \\
\text { decision-making moments }\end{array}$ \\
\hline & & $\begin{array}{l}\text { Interviews with staff in } \\
\text { collaborating services in } \\
\text { the network }\end{array}$ & $\begin{array}{l}\text { Baseline and } \\
\text { follow-up }\end{array}$ & $\begin{array}{l}\text { Qualitative/thematic changes } \\
\text { and network analysis }\end{array}$ \\
\hline \multirow[t]{4}{*}{ Mechanism } & Intervention development & $\begin{array}{l}\text { Number of education } \\
\text { workshops with service } \\
\text { staff }\end{array}$ & $\begin{array}{l}\text { Baseline and } \\
\text { intervention } \\
\text { phase }\end{array}$ & Numeric \\
\hline & & $\begin{array}{l}\text { Workshop evaluations/ } \\
\text { rating }\end{array}$ & Baseline & $\begin{array}{l}\text { Likert scale compilations and } \\
\text { comparisons }\end{array}$ \\
\hline & & $\begin{array}{l}\text { Number of distinct } \\
\text { intervention strategies } \\
\text { developed }\end{array}$ & Baseline & Numeric \\
\hline & $\begin{array}{l}\text { Intervention } \\
\text { implementation }\end{array}$ & $\begin{array}{l}\text { Number and proportion of } \\
\text { distinct strategies put into } \\
\text { practice }\end{array}$ & Intervention & Numeric \\
\hline \multirow[t]{2}{*}{ Outcomes } & $\begin{array}{l}\text { Increased proportion of } \\
\text { target group screened/ } \\
\text { referred }\end{array}$ & Service records & $\begin{array}{l}\text { From baseline to } \\
\text { follow-up }\end{array}$ & $\begin{array}{l}\text { Repeated measures of } \\
\text { proportions of client screened }\end{array}$ \\
\hline & $\begin{array}{l}\text { Increased staff } \\
\text { knowledge and practices }\end{array}$ & $\begin{array}{l}\text { Knowledge, attitudes and } \\
\text { practices survey }\end{array}$ & $\begin{array}{l}\text { Baseline and } \\
\text { follow-up }\end{array}$ & $\begin{array}{l}\text { Qualitative/thematic changes } \\
\text { and change in network } \\
\text { characteristics }\end{array}$ \\
\hline
\end{tabular}

Objective 2 intervention strategies will be designed to maximise incorporation into routine practice with little or no additional resources required. Staff working within the service are to be involved in and deliver the interventions. Researchers facilitate the work and support staff but will not implement any intervention strategies directly. The researchers will provide facilitation and support in the following ways: regular site visits (approximately one visit per month), analysis of peer-reviewed evidence to inform development of strategies, ongoing data analysis and feedback, report writing, organisation of site visit by relevant experts.

Recognising that the response from each service will be different and consistent with an action research approach, the interventions will be developed with each service separately; however, opportunities to work together and share expertise and experiences will be maximised.

\section{Data analysis}

Descriptive statistics will be used to analyse the baseline staff surveys. A comparison of survey results before and after intervention will be undertaken using paired samples $\mathrm{t}$ tests for continuous/ordinal variables, and McNemar's test for changes in categorical variables. For client surveys, no identification details are recorded and surveys are treated as cross-sectional. Descriptive statistics summarise details of client demographic characteristics. Where appropriate, independent sample t tests will be used to compare continuous/ordinal variables and $\chi^{2}$ tests will be used for categorical variables. Thematic analysis will be used to analyse all qualitative data collected during baseline, mid-term process evaluation and final evaluation.

\section{Limitations}

Although randomised controlled trials generate the most reliable evidence of intervention efficacy, the project described here develops the intervention as well as procedures to monitor implementation fidelity of the intervention. The protocol described here is a necessary preliminary step in this challenging area of research where there are no credible interventions available. If successful, the action research model augmented by a realist evaluation approach for the process evaluation will assist to inform randomised controlled trials to be implemented in similar service networks in other Australian jurisdictions and possibly other similar settings.

\section{DISCUSSION}

Although the study of cannabis use in Indigenous populations worldwide is in its infancy, there is a growing collaborative effort to address cannabis and related mental 
health issues in young Aboriginal and Torres Strait Islander people emanating from northern Australia. This work has documented sound evidence for high rates of cannabis use in remote Aboriginal and Torres Strait Islander populations. ${ }^{18} \quad 22-253043$ However, it is increasingly recognised that the issues so far documented may also have appeared in peri-urban populations of Indigenous youth. There are little data for Indigenous youth in metropolitan and regional centres. This population is hard to access because it is embedded within populations many times greater than the small discrete communities which typify remote northern Australia. To engage with such populations, it is critical that researchers work closely with the relevant community-based services being used by these young people to develop strategies that can improve their capacity to identify, refer and treat cannabis and related mental health issues. If this is not done, then young people in regional and urban centres across Australia will continue to be overlooked, leading to further marginalisation.

Evidence-based interventions for mental health and illicit drug use are crucial to confer long-lasting, sustainable mental health benefits to young Indigenous Australians. Failure to develop these will result in further long-term negative impacts on young people's workforce participation, productivity, family and community. Innovative strategies are needed to build the knowledge and capacity of practitioners, improve system-level processes and response, enhance the community and service provider network, and provide adequate support for young Indigenous people seeking help for cannabis and mental health issues.

It is anticipated that the research approach developed here can be used as a flexible intervention development model in future controlled trials in community and primary healthcare settings to improve identification and treatment of mental health and substance use in young Indigenous Australians. Implementation of this study protocol will also provide valuable data on current cannabis use rates and impacts in young Aboriginal and Torres Strait Islander Australians. It is very likely that early detection and/or early intervention strategies developed as part of the project will be incorporated into other community health services and community organisations, and it is anticipated that this model of needs assessment, intervention and evaluation will be applicable to other settings.

\section{Ethics and dissemination}

The protocol calls for results to be discussed with stakeholder organisations. Peer-reviewed publications will also be used to disseminate the findings. Findings will also be presented at national and international conferences with an Indigenous health focus and in collaboration with health service staff as opportunities to develop their research capacities emerge.
Author affiliations

${ }^{1}$ Australian Institute of Tropical Health and Medicine, James Cook University, Cairns, Queensland, Australia

2Department of Medicine, University of NSW, Sydney, New South Wales, Australia

Contributors IB and AC identified the research question, designed the study and are primary investigators in this study. IB and $K B$ drafted the manuscript. $\mathrm{IB}, \mathrm{KB}$ and $\mathrm{AC}$ all revised the manuscript critically and contributed critical revisions. IB, KB and NR will acquire the data. IB, KB, NR and $A C$ will be involved in the analysis and interpretation of the data. All authors read and approved the final manuscript.

Competing interests IB has an NHMRC Early Career Fellowship in Aboriginal and Torres Strait Islander Health, with a focus on mental health and substance misuse. She is also an Associate Research Fellow in the APHCRI Centre for Research Excellence in the Prevention of Chronic Conditions in Rural and Remote High-Risk Populations. AC leads a Community-based Health Promotion and Prevention Studies Group. He holds an NHMRC Career Development Award fellowship (\#1046773). This study was also supported by NHMRC project grant\#601002. KB is a Research Assistant with the Australian Institute of Tropical Health and Medicine, James Cook University, Community-based Health Promotion and Prevention Studies Group. She holds a Bachelor of Science from the University of Southern Queensland. NR is a Project Officer with the Australian Institute of Tropical Health and Medicine, James Cook University, Community-based Health Promotion and Prevention Studies Group. He holds a Bachelor of Arts with Honors (Anthropology) and is a PhD Candidate within the School of Arts and Social Sciences, James Cook University.

Ethics approval James Cook University, Human Research Ethics Committee (ethics approval number H5322).

Provenance and peer review Not commissioned; externally peer reviewed.

Open Access This is an Open Access article distributed in accordance with the Creative Commons Attribution Non Commercial (CC BY-NC 4.0) license, which permits others to distribute, remix, adapt, build upon this work noncommercially, and license their derivative works on different terms, provided the original work is properly cited and the use is non-commercial. See: http:// creativecommons.org/licenses/by-nc/4.0/

\section{REFERENCES}

1. Australian Institute of Health and Welfare. Young Australians: their health and wellbeing. Canberra: Australian Institute of Health and Welfare, 2007

2. Vos T, Barker B, Begg S, et al. Burden of disease and injury in Aboriginal and Torres Strait Islander Peoples: the Indigenous health gap. Int J Epidemiol 2009;38:470-7.

3. Australian Institute of Health and Welfare. The health and welfare of Australia's Aboriginal and Torres Strait Islander people: an overview. Canberra, 2011.

4. Moore THM, Zammit S, Lingford-Hughes A, et al. Cannabis use and risk of psychotic or affective mental health outcomes: a systematic review. Lancet 2007;370:319-28.

5. Hall W, Degenhardt L. Adverse health effects of non-medical cannabis use. Lancet 2009;374:1383-91.

6. Coffey C, Carlin JB, Degenhardt L, et al. Cannabis dependence in young adults: an Australian population study. Addiction 2002;97:187-94.

7. Degenhardt L, Hall W, Lynskey M. Exploring the association between cannabis use and depression. Addiction 2003;98:1493-504.

8. Bovasso GB. Cannabis abuse as a risk factor for depressive symptoms. Am J Psychiatry 2001;158:2033-37.

9. Zammit S, Moore THM, Lingford-Hughes A, et al. Effects of cannabis use on outcomes of psychotic disorders: systematic review. Br J Psychiatry 2008;193:357-63.

10. Cohen M, Solowij N, Carr V. Cannabis, cannabinoids and schizophrenia: integration of the evidence. Aust N Z J Psychiatry 2008;42:357-68.

11. Degenhardt L, Hall W. Is cannabis use a contributory cause of psychosis? Can J Psychiatry 2006;51:556-65.

12. Macleod J, Oakes R, Copello A, et al. Psychological and socia sequelae of cannabis and other illicit drug use by young people: a 
systematic review of longitudinal, general population studies. Lancet 2004;363:1579-88.

13. Grotenhermen F. Pharmacokinetics and pharmacodynamics of cannabinoids. Clin Pharmacokinet 2003;42:327-60.

14. Budney AJ, Moore BA, Vandrey RG, et al. The time course and significance of cannabis withdrawal. J Abnorm Psychol 2003;112:393.

15. Solowij N, Michie PT. Cannabis and cognitive dysfunction: parallels with endophenotypes of schizophrenia? J Psychiatry Neurosci 2007;32:30

16. Solowij N, Stephens RS, Roffman RA, et al. Cognitive functioning of long-term heavy cannabis users seeking treatment. JAMA 2002;287:1123-31.

17. Arseneault L, Cannon M, Witton J, et al. Causal association between cannabis and psychosis: examination of the evidence. $\mathrm{Br} J$ Psychiatry 2004;184:110-17.

18. Lee KSK, Conigrave KM, Clough AR, et al. Evaluation of a community-driven preventive youth initiative in Arnhem Land, Northern Territory, Australia. Drug Alcohol Rev 2008;27:75-82.

19. Crouch A, Fagan P. Communities and condoms-how difficult can it be? Aust N Z J Public Health 2012;36:506-8.

20. Fagan $\mathrm{P}$, Cannon F, Crouch $A$. The Young Person Check: screening for sexually transmitted infections and chronic disease risk in remote Aboriginal and Torres Strait Islander youth. Aust N Z J Public Health 2013;37:316-21.

21. Whiteside M, Tsey K, Crouch A, et al. Youth and Relationship Networks (YARNS): mobilising communities for sexual health. Health Promot J Austr 2012;23:226-30.

22. Bohanna I, Clough AR. Cannabis use in Cape York Indigenous communities: high prevalence, mental health impacts and the desire to quit. Drug Alcohol Rev 2012;31:580-84.

23. Clough AR, D'Abbs $P$, Cairney $S$, et al. Emerging patterns of cannabis and other substance use in Aboriginal communities in Arnhem Land Northern Territory-a study of two communities. Drug Alcohol Rev 2004;23:381-90.

24. Lee KSK, Clough AR, Jaragba MJ, et al. Heavy cannabis use and depressive symptoms in three Aboriginal communities in Arnhem Land, Northern Territory. Med J Aust 2008;188:605-09.

25. Lee KSK, Conigrave KM, Clough AR, et al. Five-year longitudinal study of cannabis users in three remote aboriginal communities in Arnhem Land, Northern territory, Australia. Drug Alcohol Rev 2009;28:623-30.

26. Australian Institute of Health and Welfare. National Drug Strategy Household Survey Report Canberra: Welfare AloHa , 2010.

27. Hunter EM, Gynther BD, Anderson CJ, et al. Psychosis in Indigenous populations of Cape York and the Torres Strait. Med J Aust 2012;196:133-5.
28. Clough AR, D'Abbs P, Cairney S, et al. Emerging patterns of cannabis and other substance use in Aboriginal communities in Arnhem Land, Northern Territory: a study of two communities. Drug Alcohol Rev 2004;23:381-90.

29. Robertson-Mcmahon J, Dowie R. Cannabis: a cloud over our community. Of Subst 2008;6:28-9.

30. Clough AR, Cairney S, D'Abbs P, et al. Measuring exposure to cannabis use and other substance use in remote aboriginal populations in Northern Australia: evaluation of a 'community epidemiology' approach using proxy respondents. Addict Res Theory 2004;12:261-74.

31. Munn-Giddings C, Winter R. A handbook for action research in health and social care. Routledge, 2013.

32. Bailie RS, Si D, O'Donoghue L, et al. Indigenous health: effective and sustainable health services through continuous quality improvement. Med J Aust 2007; 186:525.

33. Lilford R, Warren R, Braunholtz D. Action research: a way of researching or a way of managing? J Health Serv Res Policy 2003;8:100-04.

34. Australian Bureau of Statistics. Aboriginal and Torres Strait Islander wellbeing: a focus on children and youth. Australian Bureau of Statistics, 2011.

35. Martin G, Copeland J, Gilmour S, et al. The adolescent cannabis problems questionnaire (CPQ-A): psychometric properties. Addict Behav 2006;31:2238-48.

36. Kroenke K, Spitzer RL, Williams JB. The PHQ-9: validity of a brief depression severity measure. J Gen Intern Med 2001;16:606-13.

37. Spitzer RL, Kroenke K, Williams JB, et al. A brief measure for assessing generalized anxiety disorder: the GAD-7. Arch Intern Med 2006;166:1092.

38. Thomas A, Cairney S, Gunthorpe W, et al. Strong souls: development and validation of a culturally appropriate tool for assessment of social and emotional well-being in indigenous youth. Aust N Z J Psychiatry 2010;44:40-8.

39. Provan KG, Veazie MA, Staten LK, et al. The use of network analysis to strengthen community partnerships. Public Admin Rev 2005;65:603-13.

40. Luke DA, Harris JK. Network analysis in public health: history, methods, and applications. Annu Rev Public Health 2007;28:69-93.

41. Pawson R, Greenhalgh T, Harvey G, et al. Realist review-a new method of systematic review designed for complex policy interventions. J Health Serv Res Policy 2005;10(suppl 1):21-34.

42. Pawson R, Tiller N. Realistic evaluation. Sage, 1997.

43. Clough AR, d'Abbs $P$, Cairney $S$, et al. Adverse mental health effects of cannabis use in two indigenous communities in Arnhem Land, Northern Territory, Australia: Exploratory study. Aust N Z J Psychiatry 2005;39:612-20. 